\title{
Patient-derived organoids of non-small cells lung cancer and their application for drug screening
}

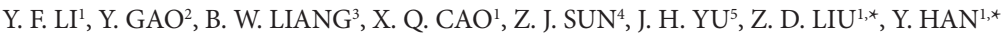 \\ ${ }^{1}$ Thoracic Surgery \#2, Beijing Tuberculosis and Thoracic Tumor Research Institute, Beijing Chest Hospital, Capital Medical University, Beijing \\ 101149, China; ${ }^{2}$ Internal Medicine-Oncology, Beijing Tuberculosis and Thoracic Tumor Research Institute, Beijing Chest Hospital, Capital \\ Medical University, Beijing 101149, China; ${ }^{3}$ Traditional Chinese Medicine Department, Beijing Tuberculosis and Thoracic Tumor Research \\ Institute, Beijing Chest Hospital, Capital Medical University, Beijing 101149, China; ${ }^{4}$ Research and Development Department, Beijing K2 Medi- \\ cal Technology Co., Ltd., Beijing 101149, China; ${ }^{5}$ Oncology Department, Wang Jing Hospital of China Academy of Chinese Medical Sciences, \\ Beijing 101149, China
}

*Correspondence: liuzhidongmed@yeah.net; hanyeecn@163.com

Received April 17, 2019 / Accepted September 4, 2019

\begin{abstract}
Patient-derived organoids (PDOs) are emerging as preclinical models with promising values in personalized cancer therapy. The purpose of this study was to establish a living biobank of PDOs from patients with non-small cell lung cancer (NSCLC) and to study the responses of PDOs to drugs. PDOs derived from NSCLC were cultured in vitro, and then treated with natural compounds including chelerythrine chloride, cantharidin, harmine, berberine and betaine with series of concentrations $(0.5-30 \mu \mathrm{M})$ for drug screening. Phenotypic features and treatment responses of established PDOs were reported. Cell lines (H1299, H460 and H1650) were used for drug screening. We successfully established a living NSCLC organoids biobank of 10 patients, which showed similar pathological features with primary tumors. Nine of the 10 patients showed mutations in EGFR. Natural compounds chelerythrine chloride, cantharidin and harmine showed anticancer activity on PDOs and cell lines. There was no significant difference in the $95 \%$ confidence interval (CI) for the IC50 value of chelerythrine chloride between PDOs $(1.56-2.88 \mu \mathrm{M})$ and cell lines $(1.45-3.73 \mu \mathrm{M}, \mathrm{p}>0.05)$. PDOs were sensitive to berberine (95\% $\mathrm{CI}, 0.092-1.55 \mu \mathrm{M})$, whereas cell lines showed a resistance $(95 \% \mathrm{CI}, 46.57-2275 \mu \mathrm{M}, \mathrm{p}<0.0001)$. PDOs had a higher IC50 value of cantharidin, and a lower IC50 value of harmine than cell lines ( $\mathrm{p}<0.05,7.50-10.45 \mu \mathrm{M}$ and 4.27-6.50 $\mu \mathrm{M}$ in PDOs, 3.07-4.44 $\mu \mathrm{M}$ and 4.69-544.99 $\mu \mathrm{M}$ in cell lines, respectively). Both PDOs and cell lines were resistant to betaine. Chelerythrine chloride showed the highest inhibitory effect in both models. Our study established a living biobank of PDOs from NSCLC patients, which might be used for high-throughput drug screening and for promising personalized therapy design.
\end{abstract}

Key words: non-small cells lung cancer, patient-derived organoids, drug screening, personalized therapy

Cell-based assays play key roles in basic research and drug screening $[1,2]$. However, conventional 2D culture (cell) model-based anticancer therapies are often restricted to clinical studies due to the tumor heterogeneity [3-7]. Cell lines reflect part of the subtypes of tumors instead of all [4-6], which restricts the drug screening and development of precision medicine, as well as personalized therapy.

Patient-derived xenograft (PDX) models and patientderived organoids (PDOs) have been exploited as new techniques for improving preclinical and personalized drug design as they recapitulate the heterogeneity of most primary tumors $[8,9]$. PDX models and PDOs have similar genomic features and functional reports to primary tumors [10-13]. In comparison with the cellular $2 \mathrm{D}$ model, the establish- ment of PDX models takes a long experimental time and is costly, and therefore is not suitable for wide usage and highthroughput drug screening $[11,14,15]$. The PDOs, however, have the characteristics of relatively shorter incubation time and lower cost than PDX models that overcomes the limited reproducibility of PDXs and reduces the higher cost of PDXs [16]. Accordingly, PDOs are a perfect combination of high reproducibility, heterogeneity, time and experimental cost [17]. Organoids of patients with colon cancer [12, 18], prostate cancer [13, 19], pancreatic cancer [20], bladder cancer [21], gastric cancer [22], liver cancer [23, 24] and non-small cell lung cancer (NSCLC) [25] have already been established. However, the huge gap between the success rates of PDOs, which ranges from 16\% [26] to 100\% [25], suggests 
both the difficulty and high efficiency of establishing living biobank of PDOs from patients with tumors and the success rate might be dependent on the cancer type.

Lung cancer is the most common malignant tumor (11.6\%) and the first leading cause of cancer-related death worldwide (18.4\%) [27]. Major causes of the high death rate of lung cancer patients are drug resistance and null clinical drug design $[28,29]$. Zhang et al. reported that cisplatin showed much higher half-maximal inhibitory concentration $\left(\mathrm{IC}_{50}\right.$ ) values in the PDOs derived from NSCLC tissues compared to the majority of NSCLC cell lines [25], thus drug screening based on PDOs might provide more precise guidelines for clinical drug treatment.

Chemical compounds that possess pharmacological and biological activities showed assistant or leader roles in clinical therapy for tumors including NSCLC [30,31], especially the compounds screened through high-throughput methods. However, the establishment of PDOs of lung cancer is relatively rare and reports only with scatted cases (1-3) were described until now $[25,32,33]$. Therefore, we established a living biobank of organoids derived from NSCLC patients ( $\mathrm{n}$ $=10$ ), and investigated the differences in the cell viability of both PDOs and three NSCLC cell lines in response to drug screening. The $\mathrm{IC}_{50}$ values of drugs in PDOs and cell lines were compared and discussed. This study is of great value for personalized therapy at least for the enrolled NSCLC patients.

\section{Patients and methods}

Patients, tissue collection, preparation and organoid establishment. Before experiments, an ethical approval (2019-48-01) was obtained from the ethics committees of Beijing Tuberculosis and Thoracic Tumor Research Institute, Beijing Chest Hospital, Capital Medical University, and written informed contents were obtained from 14 NSCLC patients. All experiments were performed following the Helsinki Declaration.

NSCLC tumor tissues were dissected, washed with cold PBS supplemented with antibiotics and cut into $\sim 5 \mathrm{~mm}^{3}$ pieces. Tumor pieces were further washed with Advanced DMEM/F12 (Thermo Fisher Scientific, Waltham, MA, USA; containing 1x Glutamax, 10 mM HEPES and antibiotics) and digested in $10 \mathrm{ml}$ medium containing $2 \%$ fetal calf serum (FCS) and $2 \mathrm{mg} / \mathrm{ml}$ collagenase (Sigma-Aldrich, St. Louis, MO, USA; Cat. No. C9407) on a shaker at $37^{\circ} \mathrm{C}$ for $1-2 \mathrm{~h}$, followed by an addition of Advanced DMEM/F12 (2\% FCS) and centrifugation at $400 \times \mathrm{g}$ for $4 \mathrm{~min}$. The pellet was further washed, resuspended and then centrifuged at $400 \times \mathrm{g}$ for 3 min. Dissociated cells were collected in Advanced DMEM/ F12 mixed in growth factor-reduced Matrigel (Corning Inc., Corning, NY, USA), which was set at $37^{\circ} \mathrm{C}$ for $30 \mathrm{~min}$ for solidification. About $500 \mu \mathrm{l}$ of complete human organoid medium (HOM) was added onto the surface of the solidified mixture of cell suspension/Matrigel.
HOM comprised of Advanced DMEM/F12 (Thermo Fisher Scientific) supplemented with series of additives as described by Lampis et al. [9] and Loredana et al. [26], including B27 ( $1 \times$, Thermo Fisher Scientific), N2 (1×, Thermo Fisher Scientific), Glutamax $(1 \times$, Thermo Fisher Scientific), HEPES (10 mM, Thermo Fisher Scientific), antibiotics (1\% penicillin-streptomycin; Gibco, Grand Island, NY, USA), bovine serum albumin (BSA, $0.01 \%$, Gibco), L-glutamine ( $2 \mathrm{mM}$, Sigma-Aldrich), recombinant human epidermal growth factor (hEGF; $50 \mathrm{ng} / \mathrm{ml}$, Invitrogen, Carlsbad, CA, USA), recombinant human fibroblast growth factor (hFGF)-10 (20 ng/ml, PeproTech, London, UK), hFGF-basic (1 ng/ml, PeproTech), Wnt3a (100 ng/ml; PeproTech), prostaglandin E2 (PGE2; $1 \mu \mathrm{M}$, R\&D Systems, Minneapolis, Minnesota, USA), nicotinaminde (10 mM, Sigma-Aldrich), noggin (100 ng/ml, PeproTech), R-spondin 1 (250 ng/ml, PeproTech), gastrin 1 (10 nM, PeproTech), A-83-01 (500 nM, PeproTech) SB202190 (10 $\mu$ M, SigmaAldrich) and $\mathrm{N}$-acetylcysteine (1 mM, Invitrogen). HOM was replaced every 2-3 days during organoids development (about one week). When the organoids reached from $200 \mu \mathrm{m}$ to $500 \mu \mathrm{m}$, a passage was performed every week. Organoids were dissociated and passaged using TrypLE Express (Gibco) following the aforementioned protocol. Recovery Cell Culture Freezing Medium (Gibco) was used for the biobanking of living organoids $\left(2 \times 10^{6}\right.$ cells/tube, at $\left.-80^{\circ} \mathrm{C}\right)$.

Sequencing analysis for EGFR mutation. The epidermal growth factor receptor (EGFR) mutation detection was performed using gene sequencing. Genomic DNA samples were isolated from all tumor tissues using a QIAamp DNA FFPE Tissue Kit (Qiagen). Mutation of the EGFR was detected using a 56 genes panel, with reference to the human reference genome.

Pathological analysis. The primary tumor tissues and PDOs were collected and cleaned using PBS $(1 \times$, Invitrogen), following with fixation in formalin (10\%, Invitrogen) and inclusion in paraffin. Sections of $5 \mu \mathrm{m}$ were subjected to hematoxylin and eosin (H\&E; Sigma-Aldrich) staining following manufacturers' instructions.

Cell lines and cell culture. Human lung cancer cell lines (EGFR wild type H1299, and H460; and EGFR mutant type H1650) were purchased from the Chinese Academy of Sciences Cell Bank (Shanghai, China). All cells were grown in RPMI-1640 medium (Gibco) or HOM (Thermo Fisher Scientific) supplemented with 2\% FCS (Gibco) and 1\% penicillin-streptavidin (Gibco) and maintained at $37^{\circ} \mathrm{C}$ in $5 \% \mathrm{CO}_{2}$.

Drug treatments. Organoids (3-5 passages) and cell lines were seeded in 96-well plates and cultured in HOM with series of concentrations $(0-30 \mu \mathrm{M})$ of natural compounds, including chelerythrine chloride, cantharidin, harmine, betaine, and berberine. All compounds were purchased from Sigma-Aldrich Inc. (St. Louis, MO, USA) and stored as $50 \mathrm{mM}$ or $10 \mathrm{mM}$ aliquots at $-80^{\circ} \mathrm{C}$. Cells and organoids were cultured with natural compounds at $37^{\circ} \mathrm{C}$ in $5 \% \mathrm{CO}_{2}$ 
for 5 days. DMSO (0.1\%) was used as negative control. Each experiment was performed at least for 3 duplicates.

Cell viability and drug sensitivity evaluation. The viability of the tumor organoids and cancer cells was determined using CellTiter-Glo 2.0 Luminescent Cell Viability Assay Kit (Promega, Madison, WI, USA) and a microplate reader (BioTek, Vermont, USA). DMSO-treated cells and tumor organoids were regarded as control. Accordingly, the $\mathrm{IC}_{50}$ values in cell lines and organoids were calculated for all compounds using nonlinear regression (curve fit) in Prism 7. The $95 \%$ confidence interval (CI) was calculated. The differences in $\mathrm{IC}_{50}$ values of drugs between the two models were tested by unpaired $t$ test. $\mathrm{P}<0.05$ was considered as statistically significant.

\section{Results}

Establishment of the living organoid biobank of NSCLC patients. A total of 14 tumor samples were derived from 14 patients (male $=6$, and female $=8$, aged $47-78$ years) with tumors at stage I-III with or without lymph node metastasis. Of the 14 tumor samples, 10 had $>50 \%$ frequency of G>A mutation at chr7:55229255 in EGFR (Table S1). After organoid induction for one week, 10 tumor tissues generated into organoids with diameter $\geq 200 \mu \mathrm{m}$, suggesting the vigorous cell viability and a success rate of $71.43 \%(10 / 14)$. Four tumor tissues failed to generate into organoids because of the low cell proliferation rate and density.

HE staining suggested that PDOs (21-35 days) had similar morphologies with the primary NSCLC tissues (Figure 1). However, the 10 PDOs of NSCLC tissues showed different histological structures between patients (heterogeneity), ranging from thin-walled cystic structures to dense structures without lumens, and were similar with that of corresponding primary NSCLC tissues.

Drug screening. The PDOs of NSCLC patients were then frozen in liquid nitrogen, stored at $-80^{\circ} \mathrm{C}$ and cultured directly before the drug screening. The cell viability of biobanked PDOs was $>95 \%$ after thawing and generated PDOs with a diameter of $>200 \mu \mathrm{m}$ after 7 days following
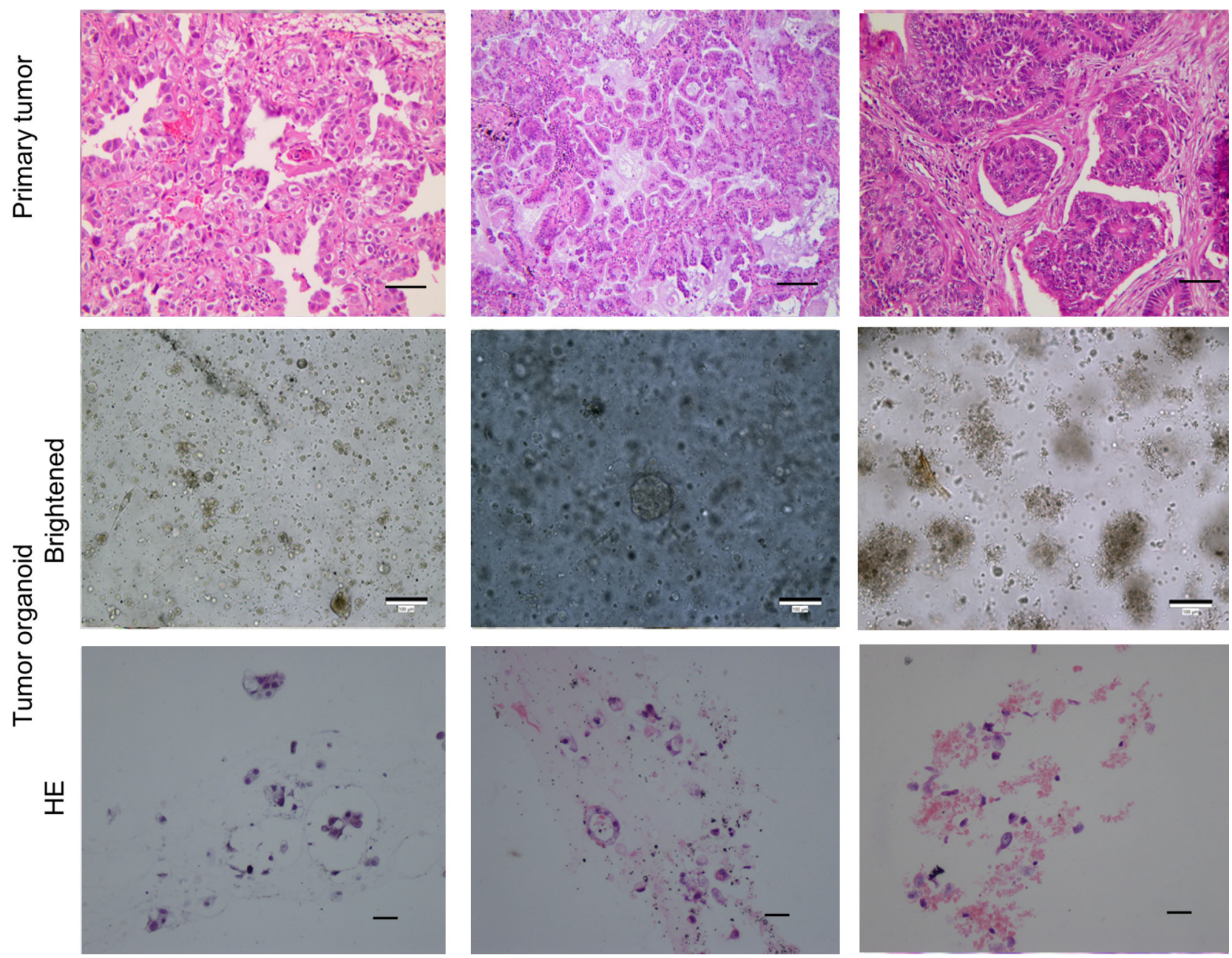

Figure 1. Histology of PDOs and primary tumor tissues from patients with NSCLC. Bar $=100 \mu \mathrm{m}$. 
HOM culture (data not shown). This suggested the high performance of the established living biobank of organoids from 10 NSCLC patients.

The PDOs and cell lines (H1299, H460 and H1650) were cultured with drugs or $0.1 \%$ DMSO (control) for 5 days, and relative cell viability was calculated accordingly. We found the 10 PDOs were sensitive to chelerythrine chloride, with low $\mathrm{IC}_{50}$ value $(95 \% \mathrm{CI}, 1.55-2.88 \mu \mathrm{M}$; Figure 2$)$. Three NSCLC cell lines (H1299, H460 and H1650) were also sensitive to chelerythrine chloride, with equivalent $\mathrm{IC}_{50}$ values (95\% CI, 1.45-3.73 $\mu \mathrm{M})$. Cantharidin and harmine showed moderate inhibitory effects on the cell viability of PDOs $\left(\mathrm{IC}_{50}\right.$ 95\% CI, 7.50-10.45 $\mu \mathrm{M}$ and $4.27-6.50 \mu \mathrm{M})$ and cell lines $\left(\mathrm{IC}_{50} 95 \% \mathrm{CI}, 3.07-4.44 \mu \mathrm{M}\right.$ and $\left.4.69-544.99 \mu \mathrm{M}\right)$, respectively. We observed that berberine had an obvious inhibitory effect on the cell viability of organoids, with low $\mathrm{IC}_{50}$ value $(95 \% \mathrm{CI}, 0.09-1.55 \mu \mathrm{M})$, but not on NSCLC cell lines $(95 \%$ CI, 46.57-2275 $\mu \mathrm{M})$. Both PDOs and cell lines were resistant to betaine (95\% CI, 153.50-9113123 $\mu \mathrm{M}$ and $14261 \mu \mathrm{M}-\infty$, respectively). The heatmap analysis of the $\log _{50}$ showed that chelerythrine chloride had the best anticancer activity and the least toxicity among the 5 compounds (Figure 3 ).

The differences in the $\mathrm{IC}_{50}$ values of drugs between the PDOs and cell lines were analyzed. There was no significant difference in the $\mathrm{IC}_{50}$ value of chelerythrine chloride and betaine between the PDOs and cell lines ( $p>0.05$; Figure 4 ). Significant differences in the $\mathrm{IC}_{50}$ values of cantharidin, harmine and berberine between two models were observed $(\mathrm{p}<0.05)$. The $\mathrm{IC}_{50}$ value of harmine and berberine in PDOs was significantly lower than that in cell lines, while the $\mathrm{IC}_{50}$ value of cantharidin in PDOs was significantly higher than that in cell lines $(\mathrm{p}<0.05)$.

\section{Discussion}

Organoids, novel stem cell-based models, are widely used for pre-clinical model establishment. A variety of tumor organoids have been established by adding a series of growth factors, including Wnt, R-spondin 1, EGF and Noggin $[9,18$, $26,34,35]$. We successfully established the living biobank of PDOs derived from 10 NSCLC patients, which showed efficacy for drug screening. We confirmed that PDOs derived from patients showed similar pathological and marked features with primary tumor tissues. The tumor cells of the 4 patients proliferated slowly and did not reach the expected level. We have compared the characteristics from patients with and without successful organoid generation and found that these four patients were in poor physical condition,
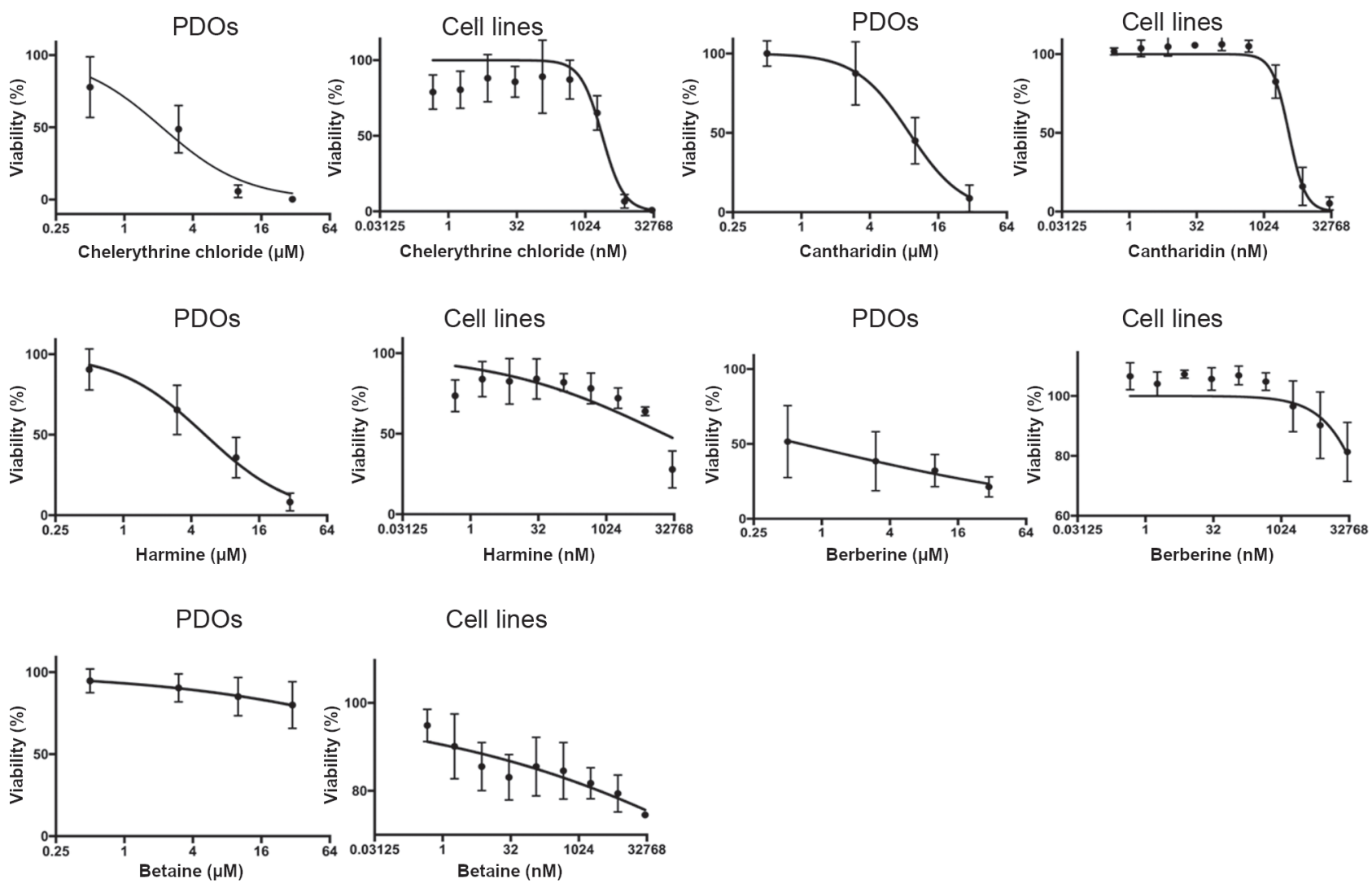

Figure 2. The relative cell viability of PDOs and NSCLC cell lines in response to drug treatments. X-axis represents the log2 transformation of the drug concentrations ( $\mu \mathrm{M}$ for PDOs and $\mathrm{nM}$ for cell lines) and the corresponding cell viability, respectively. 


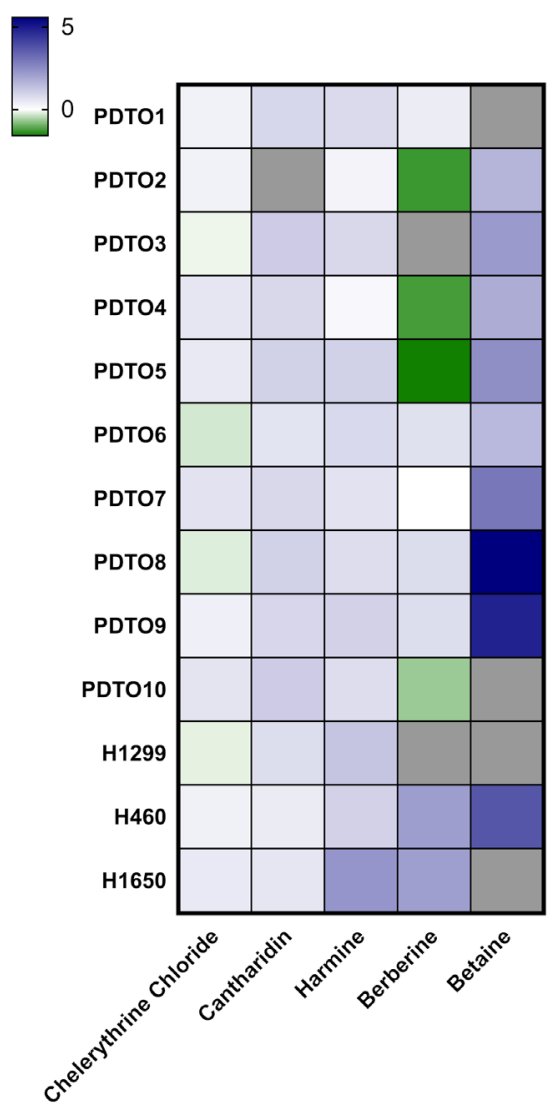

Figure 3. Heatmap analysis of the $\log \mathrm{IC}_{50}$ values of drugs in PDOs and cells.

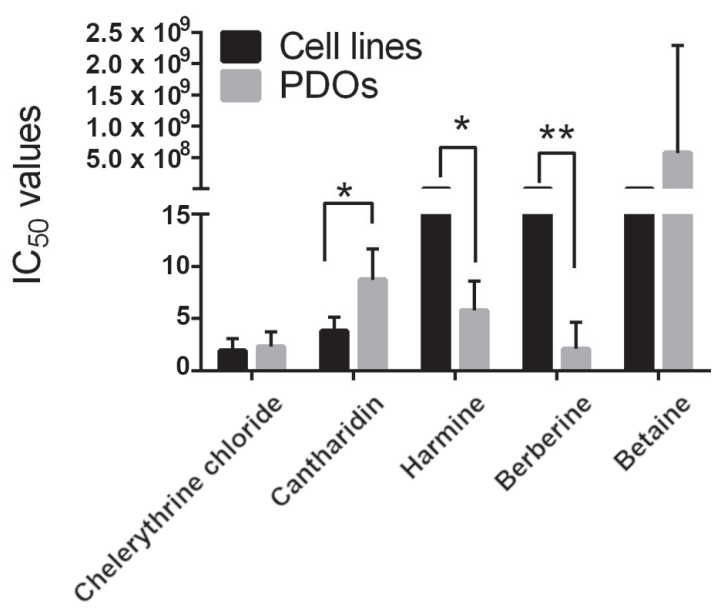

Figure 4. Comparison between the $\mathrm{IC}_{50}$ values of drugs between PDOs and cells. ${ }^{\star} \mathrm{p}<0.05$ and ${ }^{\star *} \mathrm{p}<0.01$, respectively.

which may be one of the main factors for an unsuccessful generation. Drug screening suggested that PDOs had equivalent sensitivity to chelerythrine chloride compared with NSCLC cell lines. Both models showed resistance to betaine.
Moreover, we observed that PDOs, rather than NSCLC cell lines, had an obvious sensitivity to berberine and harmine. These results might be of great value for the introduction of these compounds into personalized therapies for these 10 patients in our study.

Tumors arise from the stepwise accumulation of numerous driver alterations [36], which is mainly induced by gene instability-induced mutations and the subsequent tumor genome evolution [37]. That is the causality of tumor heterogeneity. The maintenance of genotypic and phenotypic features of the primary tumor by PDOs governs the value of these in vitro models $[38,39]$. The widely used cancer cell lines only reflect partial tumor subtypes and could not succeed tumor heterogeneity $[4-6,40]$, and therefore showed relatively low values in clinical practice compared with PDOs or PDX models [3-7]. We identified that the established PDOs, as well as the primary tumor tissues from NSCLC patients, had heterogeneity. However, PDOs basically mapped the histological structures of corresponding primary tumors. All these results suggested that there was tumor heterogeneity both between individuals and PDOs, and the PDOs inherited the heterogeneity of NSCLC patients.

It has been reported that organoids are amenable to the detection of gene-drug association [41]. The amenability of tumor organoids to high-throughput drug screening has been validated by the spectrum of genetic changes [41, 42]. PDOs show superiority to cell lines in the stability of the genetic spectrum [11, 12, 42, 43]. The significant differences in the gene expression profiles between solid tumors and corresponding cell lines have been demonstrated previously $[44,45]$. In addition to the phenotypic heterogeneity, tumor organoids maintain the physiologic changes of primary tumors, including hypoxic status, oxygen consumption, specific expression profiles of genetic and epigenetic marks, sensitivity or resistance to drugs or treatments [46]. Hence, the drug screening with established PDOs was of great value for individualized therapy for the 10 NSCLC patients.

Based on the aforementioned superiorities, PDOs recapitulate most characteristics from primary tumors, which conquer a lot of shortcomings of cell lines and effectively predict the clinical activity to compounds [10]. Studying of the drug resistance mechanisms in PDOs or PDX models helps to identify innovative and precision personalized therapies [46-48]. However, the application of PDX models usually takes too long ( $>6$ months) and is expensive, while PDOs have an acceptable period (2-3 months) and costs, which is suitable for preclinical high-throughput drug screening. Vlachogiannis et al. established a gastrointestinal PDOs living biobank and screened targeted drugs for chemotherapy [49]. They confirmed that the patients' clinical responses could be accurately recapitulated by established PDOs, with $100 \%$ sensitivity, $93 \%$ specificity, $100 \%$ negative prediction accuracy and $88 \%$ positive prediction accuracy. Our drug screening using established PDOs living biobank of NSCLC patients suggested the efficiency of PDOs applica- 
tion for drug screening. We found no significant difference between PDOs and NSCLC cell lines in the $\mathrm{IC}_{50}$ value of chelerythrine chloride. Chelerythrine chloride showed the highest inhibitory effect on PDOs and cell lines, showing the best anticancer activity. We confirmed NSCLC PDOs were sensitive to berberine (95\% CI, $0.09-1.55 \mu \mathrm{M})$, while cell lines showed resistance to it (95\% CI, 46.57-2275 $\mu \mathrm{M})$, and cantharidin had lower $\mathrm{IC}_{50}$ values in cell lines than PDOs. Berberine targets EGFR and suppresses the growth of cancer cells by inhibiting EGFR activation. We identified that all the PDOs had EGFR mutation phenotypes, with G $>$ A mutation at chr7:55229255, while two of the three cell lines (H1299 and $\mathrm{H} 460$ ) were EGFR wild type. This might be responsible for the resistance to berberine. These results showed that cell lines might have differences in drug-gene associations and genotypes from PDOs.

Chelerythrine chloride is an inhibitor of the protein kinase $\mathrm{C}$ (PKC) signaling pathway and functions by inducing tumor cell toxicity and delaying tumor growth $[50,51]$, as well as the induction of tumor cell apoptosis via mitochondrial pathway [52]. Studies have shown that chelerythrine chloride blocked the PKCzeta pathway and EGF-induced tumor cell chemotaxis in breast cancer cells [53]. Cantharidin, which is an active components of mylabris commonly used for molluscum contagiosum treatment, induces DNA damage, suppresses cell growth, activates cell autophagy and impairs cell migration and invasion via multiple signaling in lung cancer cells, including PI3K/Akt/mTOR, urokinase plasminogen activator (UPA), ERK1/2, c-Jun N-terminal kinase (JNK), nuclear factor- $\mathrm{kB}$ (NF- $\mathrm{\kappa B}$ ) and p38 mitogenactivated protein (MAP) kinase [54-56]. The anticancer activity of harmine in human cancers has been evidenced. Harmine induces proliferation inhibition, apoptosis and pro-death autophagy in gastric cells, and shows synergistic effects with paclitaxel $[57,58]$. However, the efficiency, sensitivity and specificity of these compounds in the 10 NSCLC patients should be further validated in clinical practices. In conclusion, we confirmed that the established PDOs living biobank of NSCLC patients might provide a new opportunity for drug screening and personalized therapy for these patients with NSCLC. We confirmed that all the 10 PDOs had EGFR mutation phenotypes. The drug treatments with chelerythrine chloride, cantharidin, harmine and berberine in PDOs showed the anticancer performance. Chelerythrine chloride showed the highest inhibitory activity to PDOs of NSCLC patients, followed by cantharidin and harmine. These results showed that PDOs drug screening might be a promising strategy for personalized therapy for NSCLC patients. The clinical efficiency, sensitivity and specificity of these compounds, as well as the gene-target association mechanisms underlying these compound responses in PDOs should be validated.

Supplementary information is available in the online version of the paper.
Acknowledgements: This work was supported by Scientific Research and Cultivation Program of Beijing Subordinate Hospital (PZ2018032) and Beijing Tongzhou Science and Technology Project (KJ2019CX007).

\section{References}

[1] BARRETINA J, CAPONIGRO G, STRANSKY N, VENKATESAN K, MARGOLIN AA et al. The Cancer Cell Line Encyclopedia enables predictive modelling of anticancer drug sensitivity. Nature 2012; 483: 603-607. https://doi. org/10.1038/nature11003

[2] GARNETT MJ, EDELMAN EJ, HEIDORN SJ, GREENMAN CD, DASTUR A et al. Systematic identification of genomic markers of drug sensitivity in cancer cells. Nature 2012; 483: 570-575. https://doi.org/10.1038/nature11005

[3] GARNETT MJ, EDELMAN EJ, HEIDORN SJ, GREENMAN CD, ANAHITA D et al. Systematic identification of genomic markers of drug sensitivity in cancer cells. Nature 2012; 483: 570-575. https://doi.org/10.1038/nature11005

[4] HOLLIDAY DL, SPEIRS V. Choosing the right cell line for breast cancer research. Breast Cancer Res 2011; 13: 215. https://doi.org/10.1186/bcr2889

[5] WISTUBA, II, BEHRENS C, MILCHGRUB S, SYED S, AHMADIAN $\mathrm{M}$ et al. Comparison of features of human breast cancer cell lines and their corresponding tumors. Clin Cancer Res 1998; 4: 2931-2938.

[6] BURDALL SE, HANBY AM, LANSDOWN MR, SPEIRS V. Breast cancer cell lines: friend or foe? Breast Cancer Res 2003; 5: 89-95. HTTPS://DOI.ORG/10.1186/bcr577

[7] HORVATH P, AULNER N, BICKLE M, DAVIES AM, NERY ED et al. Screening out irrelevant cell-based models of disease. Nat Rev Drug Discov 2016; 15: 751-769. https://doi. org/10.1038/nrd.2016.175

[8] JABS J, ZICKGRAF FM, PARK J, WAGNER S, JIANG X et al. Screening drug effects in patient-derived cancer cells links organoid responses to genome alterations. Mol Syst Biol 2017; 13: 955. https://doi.org/10.15252/msb.20177697

[9] LAMPIS A, CAROTENUTO P, VLACHOGIANNIS G, CASCIONE L, HEDAYAT S et al. MIR21 drives resistance to Heat Shock Protein 90 inhibition in cholangiocarcinoma. Gastroenterology 2018 ; 154: 1066-1079.e5. https://doi. org/10.1053/j.gastro.2017.10.043

[10] TENTLER JJ, TAN AC, WEEKES CD, JIMENO A, LEONG $S$ et al. Patient-derived tumour xenografts as models for oncology drug development. Nat Rev Clin Oncol 2012; 9: 338350. https://doi.org/10.1038/nrclinonc.2012.61

[11] HIDALGO M, AMANT F, BIANKIN AV, BUDINSKA E, BYRNE AT et al. Patient-derived xenograft models: an emerging platform for translational cancer research. Cancer Discov 2014; 4: 998-1013. https://doi.org/10.1158/21598290.Cd-14-0001

[12] VAN DE WETERING M, FRANCIES HAYLEY E, FRANCIS JOSHUA M, BOUNOVA G, IORIO F et al. Prospective Derivation of a Living Organoid Biobank of Colorectal Cancer Patients. Cell 2015; 161: 933-945. https://doi.org/10.1016/j. cell.2015.03.053 
[13] GAO D, VELA I, SBONER A, IAQUINTA PJ, KARTHAUS WR et al. Organoid cultures derived from patients with advanced prostate cancer. Cell 2014; 159: 176-187. https://doi. org/10.1016/j.cell.2014.08.016

[14] HIDALGO M, BRUCKHEIMER E, RAJESHKUMAR NV, GARRIDO-LAGUNA I, DE OLIVEIRA E et al. A Pilot Clinical Study of Treatment Guided by Personalized Tumorgrafts in Patients with Advanced Cancer. Mol Cancer Ther 2011; 10: 1311-1316. https://doi.org/10.1158/1535-7163.MCT-110233

[15] BRUNA A, RUEDA OM, GREENWOOD W, BATRA AS, CALLARI $\mathrm{M}$ et al. A biobank of breast cancer explants with preserved intra-tumor heterogeneity to screen anticancer compounds. Cell 2016; 167: 260-274.e22. https://doi. org/10.1016/j.cell.2016.08.041

[16] NEAL JT, KUO CJ. Organoids as Models for Neoplastic Transformation. Annu Rev Pathol 2016; 11: 199-220. https:// doi.org/10.1146/annurev-pathol-012615-044249

[17] WEEBER F, OOFT SN, DIJKSTRA KK, VOEST EE. Tumor Organoids as a Pre-clinical Cancer Model for Drug Discovery. Cell Chem Biol 2017; 24: 1092-1100. https://doi. org/10.1016/j.chembiol.2017.06.012

[18] SATO T, STANGE DE, FERRANTE M, VRIES RG, VAN ES $\mathrm{JH}$ et al. Long-term expansion of epithelial organoids from human colon, adenoma, adenocarcinoma, and Barrett's epithelium. Gastroenterology 2011; 141: 1762-1772. https:// doi.org/10.1053/j.gastro.2011.07.050

[19] KARTHAUS WR, IAQUINTA PJ, DROST J, GRACANIN A, VAN BOXTEL $R$ et al. Identification of multipotent luminal progenitor cells in human prostate organoid cultures. Cell 2014; 159: 163-175. https://doi.org/10.1016/j. cell.2014.08.017

[20] BOJ SF, HWANG CI, BAKER LA, CHIO, II, ENGLE DD et al. Organoid models of human and mouse ductal pancreatic cancer. Cell 2015; 160: 324-338. https://doi.org/10.1016/j. cell.2014.12.021

[21] LEE SH, HU W, MATULAY JT, SILVA MV, OWCZAREK TB et al. Tumor Evolution and Drug Response in PatientDerived Organoid Models of Bladder Cancer. Cell 2018; 173: 515-528.e517. https://doi.org/10.1016/j.cell.2018.03.017

[22] BARTFELD S, BAYRAM T, VAN DE WETERING $M$, HUCH M, BEGTHEL $H$ et al. In vitro expansion of human gastric epithelial stem cells and their responses to bacterial infection. Gastroenterology 2015; 148: 126-136.e126. https://doi.org/10.1053/j.gastro.2014.09.042

[23] HUCH M, BOJ SF, CLEVERS H. Lgr5(+) liver stem cells, hepatic organoids and regenerative medicine. Regen Med 2013; 8: 385-387. https://doi.org/10.2217/rme.13.39

[24 HUCH M, GEHART H, VAN BOXTEL R, HAMER K, BLOKZIJL $\mathrm{F}$ et al. Long-term culture of genome-stable bipotent stem cells from adult human liver. Cell 2015; 160: 299-312. https://doi.org/10.1016/j.cell.2014.11.050

[25] ZHANG Z, WANG H, DING Q, XING Y, XU Z et al. Establishment of patient-derived tumor spheroids for non-small cell lung cancer. Plos One 2018; 13: e0194016. https:/doi. org/10.1371/journal.pone.0194016
[26] PUCA L, BAREJA R, PRANDI D, SHAW R, BENELLI M et al. Patient derived organoids to model rare prostate cancer phenotypes. Nat Commun 2018; 9: 2404. https://doi. org/10.1038/s41467-018-04495-Z

[27] BRAY F, FERLAY J, SOERJOMATARAM I, SIEGEL RL, TORRE LA et al. Global cancer statistics 2018: GLOBOCAN estimates of incidence and mortality worldwide for 36 cancers in 185 countries. CA Cancer J Clin 2018; 68: 394-424. https://doi.org/10.3322/caac.21492

[28] SUN X, BAO J, SHAO Y. Mathematical Modeling of Therapy-induced Cancer Drug Resistance: Connecting Cancer Mechanisms to Population Survival Rates. Sci Rep 2016; 6: 22498. https://doi.org/10.1038/srep22498

[29] KAUR P, GARG T, RATH G, MURTHY RS, GOYAL AK. Surfactant-based drug delivery systems for treating drugresistant lung cancer. Drug Deliv 2016; 23: 727-738. https:// doi.org/10.3109/10717544.2014.935530

[30] HUGHES JP, REES S, KALINDJIAN SB, PHILPOTT KL. Principles of early drug discovery. Brit J Pharmacol 2011; 162: 1239-1249. https://doi.org/10.1111/j.14765381.2010.01127.x

[31] CLARDY J, WALSH C. Lessons from natural molecules. Nature 2004; 432: 829-837. https://doi.org/10.1038/nature03194

[32] JORDI B, GIORDANO C, NICOLAS S, KAVITHA V, MARGOLIN AA et al. The Cancer Cell Line Encyclopedia enables predictive modelling of anticancer drug sensitivity. Nature 2012; 483: 603-607. https://doi.org/10.1038/nature11003

[33] LI Y, GUO X-H, DANG Y-R, SUN L-L, ZHANG X-Y et al. Complete genome sequence of Arcticibacterium luteifluviistationis SM1504T, a cytophagaceae bacterium isolated from Arctic surface seawater. Stand Genomic Sci 2018; 13: 33. https://doi.org/10.1186/s40793-018-0335-x

[34] CLEVERS H. Modeling Development and Disease with Organoids. Cell 2016; 165: 1586-1597. https://doi.org/10.1016/j. cell.2016.05.082

[35] SATO T, VRIES RG, SNIPPERT HJ, VAN DE WETERING M, BARKER N et al. Single Lgr5 stem cells build crypt-villus structures in vitro without a mesenchymal niche. Nature 2009; 459: 262-265. https://doi.org/10.1038/nature07935

[36] FEARON ER, VOGELSTEIN B. A genetic model for colorectal tumorigenesis. Cell 1990; 61: 759-767. https://doi. org/10.1002/gcc.2870040112

[37] BURRELL RA, MCGRANAHAN N, BARTEK J, SWANTON C. The causes and consequences of genetic heterogeneity in cancer evolution. Nature 2013; 501: 338-345. https:// doi.org/10.1038/nature12625

[38] RUSSO M, SIRAVEGNA G, BLASZKOWSKY LS, CORTI G, CRISAFULLI G et al. Tumor Heterogeneity and Lesion-Specific Response to Targeted Therapy in Colorectal Cancer. Cancer Discov 2016; 6: 147-153. https://doi. org/10.1158/2159-8290.Cd-15-1283

[39] RUBIN EH, GILLILAND DG. Drug development and clinical trials--the path to an approved cancer drug. Nat Rev Clin Oncol 2012; 9: 215-222. https://doi.org/10.1038/nrclinonc. 2012.22 
[40] IORIO F, KNIJNENBURG TA, VIS DJ, BIGNELL GR, MENDEN MP et al. A Landscape of Pharmacogenomic Interactions in Cancer. Cell 2016; 166: 740-754. https://doi. org/10.1016/j.cell.2016.06.017

[41] VANDEWETERING M, FRANCIES H, FRANCIS J, BOUNOVA G, IORIO F et al. Prospective Derivation of a Living Organoid Biobank of Colorectal Cancer Patients. Cell 2015; 161: 933-945. https://doi.org/10.1016/j.cell.2015.03.053

[42] DOMCKE S, SINHA R, LEVINE DA, SANDER C, SCHULTZ N. Evaluating cell lines as tumour models by comparison of genomic profiles. Nat Commun 2013; 4: 2126. https://doi. org/10.1038/ncomms3126

[43] PAULI C, HOPKINS BD, PRANDI D, SHAW R, FEDRIZZI $T$ et al. Personalized In Vitro and In Vivo Cancer Models to Guide Precision Medicine. Cancer Discov 2017; 7: 462-477. https://doi.org/10.1158/2159-8290.Cd-16-1154

[44] STEIN WD, LITMAN T, FOJO T, BATES SE. A Serial Analysis of Gene Expression (SAGE) database analysis of chemosensitivity: comparing solid tumors with cell lines and comparing solid tumors from different tissue origins. Cancer Res 2004; 64: 2805-2816. https://doi.org/10.1158/0008-5472. can-03-3383

[45] SZAKACS G, GOTTESMAN MM. Comparing solid tumors with cell lines: implications for identifying drug resistance genes in cancer. Mol Interv 2004; 4: 323-325. https://doi. org/10.1124/mi.4.6.5

[46] LING H, AUDREY H, ISHAAN J, MICHAEL BG, INES L et al. Ductal pancreatic cancer modeling and drug screening using human pluripotent stem cell- and patient-derived tumor organoids. Nat Med 2015; 21: 1364-1371. https://doi. org/10.1038/nm.3973

[47] BERTOTTI A, MIGLIARDI G, GALIMI F, SASSI F, TORTI D et al. A molecularly annotated platform of patientderived xenografts ("xenopatients") identifies HER2 as an effective therapeutic target in cetuximab-resistant colorectal cancer. Cancer Discov 2011; 1: 508-523. https://doi. org/10.1158/2159-8290.Cd-11-0109

[48] LETO SM, SASSI F, CATALANO I, TORRI V, MIGLIARDI $\mathrm{G}$ et al. Sustained Inhibition of HER3 and EGFR Is Necessary to Induce Regression of HER2-Amplified Gastrointestinal Carcinomas. Clin Cancer Res 2015; 21: 5519-5531. https:// doi.org/10.1158/1078-0432.Ccr-14-3066

[49] VLACHOGIANNIS G, HEDAYAT S, VATSIOU A, JAMIN Y, FERNANDEZ-MATEOS J et al. Patient-derived organoids model treatment response of metastatic gastrointestinal cancers. Science (New York, N.Y.) 2018; 359: 920-926. https:// doi.org/10.1126/science.aao2774
[50] CHMURA SJ, MAUCERI HJ, ADVANI S, HEIMANN R, BECKETT MA et al. Decreasing the apoptotic threshold of tumor cells through protein kinase $\mathrm{C}$ inhibition and sphingomyelinase activation increases tumor killing by ionizing radiation. Cancer Res 1997; 57: 4340-4347.

[51] CHMURA SJ, DOLAN ME, CHA A, ., MAUCERI HJ, KUFE DW et al. In vitro and in vivo activity of protein kinase $\mathrm{C}$ inhibitor chelerythrine chloride induces tumor cell toxicity and growth delay in vivo. Clin Cancer Res 2000; 6: 737-742.

[52] ZHANG ZF, GUO Y, ZHANG JB, WEI XH. Induction of apoptosis by chelerythrine chloride through mitochondrial pathway and Bcl-2 family proteins in human hepatoma SMMC-7721 Cell. Arch Pharm Res 2011; 34: 791-800. https://doi.org/10.1007/s12272-011-0513-5

[53] SUN R, GAO P, CHEN L, MA D, WANG J et al. Protein kinase $\mathrm{C}$ zeta is required for epidermal growth factor-induced chemotaxis of human breast cancer cells. Cancer Res 2005; 65: 1433-1441. https://doi.org/10.1158/0008-5472.Can-041163

[54] HSIA TC, YU CC, HSIAO YT, WU SH, BAU DT et al. Cantharidin Impairs Cell Migration and Invasion of Human Lung Cancer NCI-H460 Cells via UPA and MAPK Signaling Pathways. Anticancer Res 2016; 36: 5989-5997. https://doi. org/10.21873/anticanres.11187

[55] HSIA TC, LIN JH, HSU SC, TANG NY, LU HF et al. Cantharidin induces DNA damage and inhibits DNA repairassociated protein levels in NCI-H460 human lung cancer cells. Environ Toxicol 2015; 30: 1135-1143. https://doi. org/10.1002/tox.21986

[56] LIU YP, LI L, XU L, DAI EN, CHEN WD. Cantharidin suppresses cell growth and migration, and activates autophagy in human non-small cell lung cancer cells. Oncol Lett 2018; 15: 6527-6532. https://doi.org/10.3892/ol.2018.8141

[57] LI C, WANG Y, WANG C, YI X, LI M et al. Anticancer activities of harmine by inducing a pro-death autophagy and apoptosis in human gastric cancer cells. Phytomedicine 2017; 28: 10-18. https://doi.org/10.1016/j.phymed.2017.02.008

[58] YU XJ, SUN K, TANG XH, ZHOU CJ, SUN H et al. Harmine combined with paclitaxel inhibits tumor proliferation and induces apoptosis through down-regulation of cyclooxygenase-2 expression in gastric cancer. Oncol Lett 2016; 12: 983-988. https://doi.org/10.3892/ol.2016.4696 


\section{Patient-derived organoids of non-small cells lung cancer and their application for drug screening}

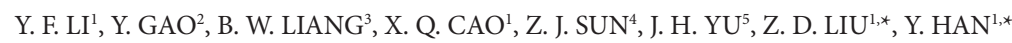

Supplementary Information

Suppl. Table S1. Mutation of EGFR in the 14 patients.

\begin{tabular}{|c|c|c|c|c|c|c|c|c|c|c|c|c|c|c|}
\hline Patient & 1 & 2 & 3 & 4 & 5 & 6 & 7 & 8 & 9 & 10 & 11 & 12 & 13 & 14 \\
\hline Gender & $\mathrm{F}$ & $\mathrm{F}$ & M & $\mathrm{F}$ & M & $\mathrm{M}$ & $\mathrm{F}$ & $\mathrm{M}$ & F & M & F & M & M & $\mathrm{F}$ \\
\hline Stage & IV & IIb & $\mathrm{Ib}$ & IV & IV & IIIb & IV & IIa & IV & Ia & IIIb & IV & IV & IV \\
\hline Age & 73 & 72 & 65 & 55 & 83 & 73 & 81 & 44 & 53 & 86 & 35 & 65 & 68 & 62 \\
\hline $\begin{array}{l}\text { Frequency of EGFR mutation } \\
(55229255-55229255)\end{array}$ & 99 & 99.82 & 52.55 & 100 & 0 & 0 & 99.78 & 100 & 99.84 & 46.82 & 0 & 86.74 & 99.94 & 16.28 \\
\hline $\begin{array}{l}\text { Frequency of EGFR mutation } \\
(55242485-55242485)\end{array}$ & 0 & 0 & 0 & 0 & 17.67 & 0 & 0 & 0 & 0 & 0 & 0 & 0 & 0 & 0 \\
\hline PDO (Yes/No) & Yes & Yes & Yes & Yes & Yes & Yes & Yes & Yes & Yes & Yes & No & No & No & No \\
\hline
\end{tabular}

